\title{
Incidência dos casos de Dengue (2011-2017), Zika e Febre Chikungunya (2016-2017)
}

\section{em Balsas, Maranhão}

Cases incidence of Dengue (2011-2017), Zika and Febre Chikungunya (2016-2017) at Balsas, Maranhão

Incidencia de los casos de Dengue (2011-2017), Zika y Febre Chikungunya (2017-2017) en Balsas, Maranhão

Paulo Henrique Silva Lopes

ORCID: https://orcid.org/0000-0002-1258-5013 Universidade Federal do Maranhão, Brasil E-mail phlopes1800@gmail.com Layla Karolyne Dourado Stragliotto ORCID: https://orcid.org/0000-0001-8571-4771 Universidade Federal do Maranhão, Brasil. E-mail: laystragliotto@gmail.com

Gleiciane Santana de Miranda ORCID: https://orcid.org/0000-0002-1145-2868 Universidade Federal do Maranhão, Brasil e-mail: gleiciany.style.miranda@gmail.com

Débora Batista Pinheiro Sousa

ORCID: https://orcid.org/0000-0002-5104-4869 Universidade Federal do Maranhão, Brasil e-mail: debora.batista@ufma.br

\begin{abstract}
Resumo
As arboviroses são doenças causadas pelos arbovírus, dentre elas inclui-se o vírus da Dengue, Zika, febre Chikungunya e engloba todos aqueles transmitidos por artrópodes, (insetos e aracnídeos). Neste estudo foram analisadas duas variáveis: a incidência dos casos de Dengue, Zika e febre Chikungunya por mesmo mês, e a mensal de índice pluviométrico do município de Balsas Maranhão, através do site do Instituto Nacional de Meteorologia. Pelo estudo de gráficos observou-se a precipitação média relacionada aos casos das três doenças em questão. Notou-se que a quantidade de chuva foi um item importante relacionado à incidência dos casos: Zika vírus e febre Chikungunya tiveram uma maior frequência no período de estiagem enquanto a incidência do vírus da Dengue foi maior no período chuvoso. Como Balsas é destaque por ser um dos grandes centros urbanos do sul da Maranhão, e contar com atendimento hospitalar de cidadãos de municípios vizinhos, é importante que haja a interiorização de laboratórios de referência para deteç̧ão de agentes etiológicos dos vetores assim como ações contínuas de vigilância e controle epidemiológico do A. egypti.
\end{abstract}

Palavras-chave: Arbovírus, Epidemiologia; Incidência; Saúde pública; Vetores; Sul do Maranhão.

\begin{abstract}
Arboviruses are diseases caused by arboviruses, including the Dengue virus, Zika, Chikungunya fever, and includes all those transmitted by arthropods (insects and arachnids). In this study two variables were analyzed: the incidence of Dengue, Zika and Chikungunya fever cases for the same month, and the monthly rainfall index of the municipality of Balsas Maranhão, through the website of the National Meteorological Institute. Through the graph study the average precipitation related to the cases of the three diseases in question was observed. It was observed that the amount of rainfall was an important item related to the incidence of the cases: Zika virus and Chikungunya fever had a higher frequency in the dry season while the incidence of Dengue virus was higher in the rainy season. As Balsas is outstanding because it is one of the great urban centers of the south of Maranhão, and it counts on hospital attendance of citizens of neighboring municipalities, it is important that there is the internalization of laboratories of reference for the detection of etiological agents of the vectors as well as continuous surveillance actions and epidemiological control of A. egypti. Keywords: Arbovirus; Epidemiology; Incidence; Health; Vectors; South Maranhão.
\end{abstract}

\section{Resumen}

Las arbovirosis son enfermedades causadas por los arbovirus, entre ellas se incluye el virus del Dengue, Zika, fiebre Chikungunya y engloba a todos aquellos transmitidos por artrópodos, (insectos y arácnidos). En este estudio se 
analizaron dos variables: la incidencia de los casos de Dengue, Zika y fiebre Chikungunya por mes, y la mensual de índice pluviométrico del municipio de Balsas Maranhão, a través del sitio del Instituto Nacional de Meteorología. Por el estudio de gráficos se observó la precipitación media relacionada a los casos de las tres enfermedades en cuestión. Se observó que la cantidad de lluvia fue un elemento importante relacionado con la incidencia de los casos: Zika virus y fiebre Chikungunya tuvieron una mayor frecuencia en el período de sequía mientras la incidencia del virus del Dengue fue mayor en el período lluvioso. Como Balsas es destaque por ser uno de los grandes centros urbanos del sur de Maranhão, y contar con atención hospitalaria de ciudadanos de municipios vecinos, es importante que haya la interiorización de laboratorios de referencia para detección de agentes etiológicos de los vectores así como acciones continuas de vigilancia y control epidemiológico del A. egypti.

Palabras clave: Arbovírus; Epidemiologia; Incidência; Salud; Vectores; Sul do Maranhão.

\section{Introdução}

A partir da década de 50, o Brasil passou a apresentar um processo de urbanização cada vez mais acelerado, principalmente pela intensidade da industrialização, mais especificamente, a partir da segunda metade do século XX (Araújo, 2009). Dessa forma, o crescimento urbano impactado pelo desenvolvimento econômico afetou negativamente a saúde da população, principalmente pelo planejamento inadequado de novas áreas habitacionais que foram surgindo ao longo dos anos, favorecendo assim a emergência de potenciais vetores geradores de arboviroses na população (Araújo, 2009).

Nesse contexto, de acordo com Lopes (2014), os arbovírus são transmitidos por artrópodes, usualmente hematófagos. São caracterizados não somente pelo agente de transmissão vetorial, mas também por apresentarem ciclo de replicação exógeno ao hospedeiro definitivo, dentro do inseto (Lopes, 2014). As arboviroses têm representado um grande desafio à saúde pública, devido às mudanças climáticas e ambientais e aos desmatamentos que favorecem a amplificação e a transmissão viral, além da transposição da barreira entre espécies.

Atualmente, existem aproximadamente 545 espécies de arbovírus, onde 150 estão relacionadas às doenças em seres humanos, sendo a maioria zoonótica. No Brasil, as condições climáticas tropicais são favoráveis para a circulação e manutenção do ciclo de vida dos arbovírus. Em 2015 circularam pelo menos nove arbovírus patogênicos, nas quais se destacam: o vírus da Dengue (família Flaviviridae), Zika (família Flaviviridae) e o da febre chikungunya (família Togaviridae), todos transmitidos pelo mosquito Aedes aegypti. Em 2016 foram registrados 1.054 .127 casos prováveis de Dengue, 64.349 de febre Chikungunya e 120.161 de doença Aguda pelo vírus Zika (Figueiredo, 2015).

A Dengue, febre Chikungunya e o Zika vírus têm se mostrado doenças reemergentes nos últimos anos. No Brasil, constitui-se um dos principais problemas de saúde pública por seu elevado grau de morbidade e mortalidade.

De acordo com (Oliveira, 2016; Oliveira et al., 2020), os dados que foram divulgados pelo Ministério da Saúde (Brasil, 2014) mostram que casos de notificação de doenças transmitidas pelo Aedes, como a Dengue, vêm aumentando no país, sendo que a região Nordeste aparece na terceira posição do ranking (19.689 casos; 9,2\%) e, dentre os estados da referida região, o Rio Grande do Norte ocupa a terceira posição em número de casos notificados de Dengue em taxa de incidência (por 100.000 hab.). Quanto à febre Chikungunya, os casos só começaram a ser notificados em setembro de 2014. O conhecimento do número de casos se deu mais especificamente na Semana Epidemiológica (SE) conforme os boletins do Ministério da Saúde (MS) nº 36 (Brasil, 2015). Quanto ao Zika, também transmitido pelo A. aegypti, os casos da doença têm sido notificados nos bancos de dados do Sistema de Informação de Agravos de Notificação (SINAN); tendo surgido as notificações a partir da segunda semana de novembro de 2015, como mostra o Boletim da SE nº 45 (Brasil, 2018).

No Estado do Maranhão, a situação desses arbovírus não é diferente do contexto nacional e nem mundial, pois ultimamente no Brasil e no mundo a incidência desses vírus vem acarretando uma série de problemas e agravo à saúde pública. A ocorrência dessas doenças causada por um único vetor traz inúmeros casos no Maranhão por ser um estado onde o clima tropical predomina ao longo de todo o ano e pela falta de novas tecnologias disponíveis que dão um diagnóstico eficiente e mais rápido (Maranhão, 2018). 
Apesar da existência de trabalhos relacionados ao estudo do vetor e à ocorrência de casos da doença no país pouca atenção tem - se dado aos municípios localizados no bioma Cerrado, onde o regime de chuvas é diferenciado. Além disso, o mosquito A. aegypti representa um importante vetor de arboviroses, com impactos diretos à saúde da população de todo país. Na região sul do maranhão cidades como Imperatriz, Carolina e Paraibano, possui $2.4 \%, 0.34 \%$ e $4.54 \%$, respectivamente, de suas casas infestação do mosquito. Além disso, dentre as 17 cidades que fazem parte da região sul do maranhão, em $70,6 \%$ (12 cidades) foram detectados a presença do A. Aegypti como vetor dos casos de dengue (Rebêlo et al., 1999; Oliveira et al., 2020).

Dessa forma, acompanhar a incidência dos casos de Dengue, Zika e febre Chikungunya são uma ferramenta relevante para implantação de políticas públicas locais. Para tanto, o presente artigo tem por objetivo descrever a incidência dos casos de Dengue, Zika e febre Chikungunya, através dos registros pluviométricos em Balsas, Maranhão.

\section{Metodologia}

\section{1 Área de estudo}

O município de Balsas (Figura 1) está inserido no bioma Cerrado e localiza-se no extremo sul do Maranhão, entre as coordenadas 07³1'58’' S e 4602' 09’ W. Em 2016, Balsas possuía uma população de aproximadamente 94.779 habitantes, dos quais $90 \%$ residiam na área urbana, distribuídos em $7.859 \mathrm{~km}^{2}$ de área territorial dotada de centro comercial e agroindustrial em amplo desenvolvimento.

Figura 1: Localização do município de Balsas, Maranhão.

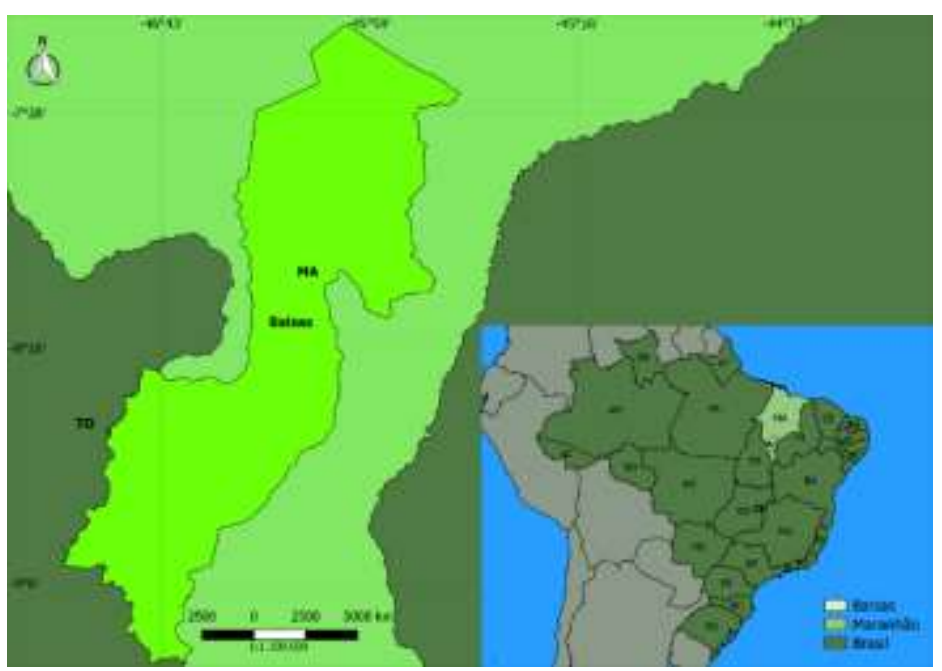

Fonte: Autores.

\subsection{Tipo de estudo}

Este trabalho trata-se de um estudo epidemiológico descritivo (Lima-Costa, 2003), que visa determinar como a doença em estudo se dissemina sob determinadas condições, sendo elas, o tempo, lugar e como esses casos, sendo eles novos ou já existentes, impactam a saúde dos indivíduos infectados e as pessoas as quais elas estão relacionadas. Dessa forma, o mesmo foi realizado a partir de dados secundários, estes, obtidos na Secretaria Municipal de Saúde do município de Balsas sobre a incidência de Dengue, Zika e febre Chikungunya no município, tendo em vista que Balsas foi o segundo município com a maior prevalência da febre Chikungunya no de 2016 (Balsas, 2016). Os dados utilizados sobre o caso de doenças corresponderam ao período de 2011 - 2017 para a Dengue, 2016 e 2017 para a Zika e febre Chikungunya.

Foram analisadas as seguintes variáveis. 
a) Incidência dos casos de Dengue, Zika e febre Chikungunya por mesmo mês, ano de notificação e sexo;

b) Relação mensal de índice pluviométrico do município de Balsas (INMET (2018).

\subsection{Aspectos éticos da pesquisa}

Os dados referentes aos casos da doença foram obtidos exclusivamente de fontes secundárias (dados oficiais e de domínio público), sem identificação dos pacientes, de modo que foi dispensada a aprovação do projeto do estudo por Comitê de Ética em Pesquisa, em conformidade com a Resolução do Conselho Nacional de Saúde (CNS) nº 466, de 12 de dezembro de 2012.

\subsection{Análise dos dados}

A análise dos dados foi realizada pela exploração a partir de dados secundários, estes obtidos na Secretaria Municipal de Saúde do município de Balsas sobre a incidência de Dengue, Zika e febre Chikungunya. Quanto aos dados pluviométricos, os mesmos foram obtidos da base da dados do Instituto Nacional de Meteorologia - INMET para os anos referidos. sendo os mesmos analisados e tabulados utilizando o software Microsoft Excel 2019, incluso no pacote Microsoft Office 2019. Após estas etapas, foi levada em consideração a frequência dos dados para a representação na forma de gráficos e tabelas, os quais foram utilizados para a interpretação dos mesmos tomando-se como aporte a literatura referente à temática.

\section{Resultados e Discussão}

A Figura 2 mostra a precipitação pluviométrica média e os casos de incidência de Dengue entre 2011 - 2017. A precipitação média nos anos de 2011 a 2017 relacionado aos casos de Dengue em Balsas - Maranhão. Nos meses de fevereiro e maio a ocorrência da doença foi maior, devido aos altos índices pluviométricos na região. Além disso, apesar do mês de janeiro apresentar uma maior precipitação no gráfico, não houve muitos casos da incidência de dengue.

Figura 2: Precipitação pluviométrica média e casos de Dengue no município de Balsas - MA entre 2011-2017.

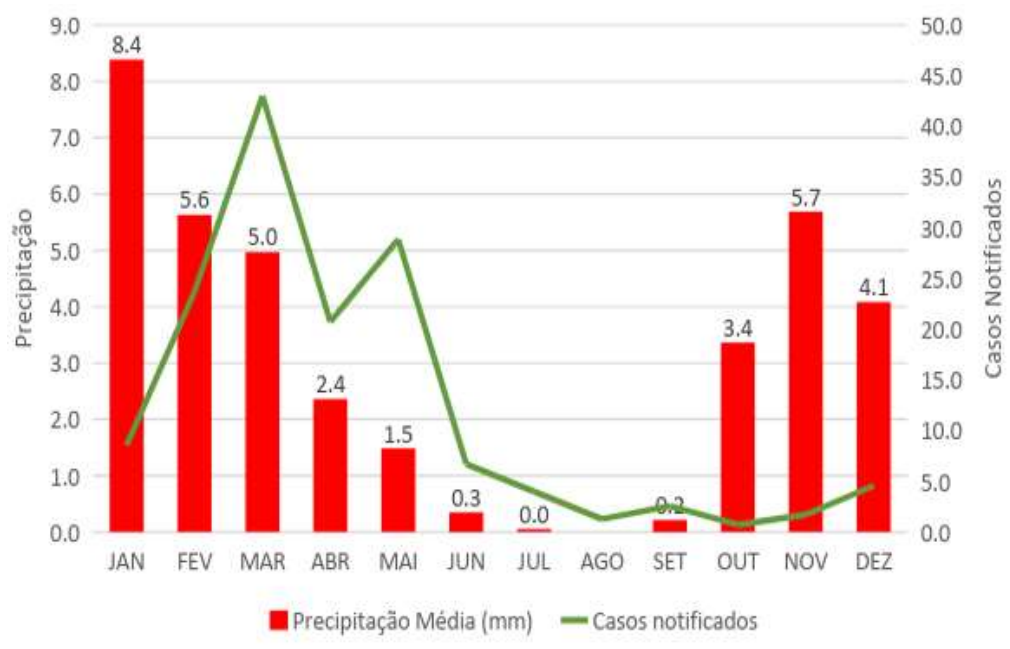

Fonte: Sec. Municipal de Saúde de Balsas - MA.

A Dengue é uma doença de etiologia viral transmitida aos homens por mosquitos, por isso é classificada como uma arbovirose. Segundo Gubler (2004); Medeiros et al. (2021), dentre todas as arboviroses conhecidas, a Dengue é considerada a única completamente adaptada aos seres humanos, que mantém a circulação dos vírus em áreas urbanas, especialmente as grandes cidades de países tropicais. 
Por apresentar-se com sintomas semelhantes às de muitas outras doenças infecciosas, o contexto espaço-temporal (ex. se o local é endêmico/epidêmico) e as informações laboratoriais são imprescindíveis para se determinar com exatidão, se as causas desses sintomas, são ocasionadas pela infecção por vírus do dengue (Cartão, 2011). Cordeiro (2008) assinala que os sintomas podem variar por: faixa etária, cepa e sorotipo do vírus infectante, local e o tempo da infecção; reiterando a necessidade de confirmação laboratorial, especialmente em períodos não epidêmicos.

Em contrapartida, o vírus Zika foi originalmente isolado em mosquitos da espécie Aedes (Stegomyia) africanus e macacos do gênero Rhesus na Floresta Zika (por isso recebeu essa nomeação), localizada próximo de Entebbe na Uganda, em 1947 e isolado pela primeira vez em um ser humano na Nigéria em 1954 (Oliveira, 2016; Souza Martinuci et al., 2020).

Dessa forma, a Figura 3 mostra a relação da precipitação pluviométrica média e os casos de incidência de Zika vírus entre 2016-2017. A precipitação pluviométrica nos anos de 2016 a 2017 mostrou que os casos de Zika no município de Balsas começaram a aumentar a partir do mês de fevereiro, atingindo um maior pico no mês de maio. A partir do mês de junho, quando inicia o período de estiagem na região, a incidência de Zika na região diminui.

Figura 3: Precipitação pluviométrica média e casos de Zika no município de Balsas - MA entre 2016-2017.

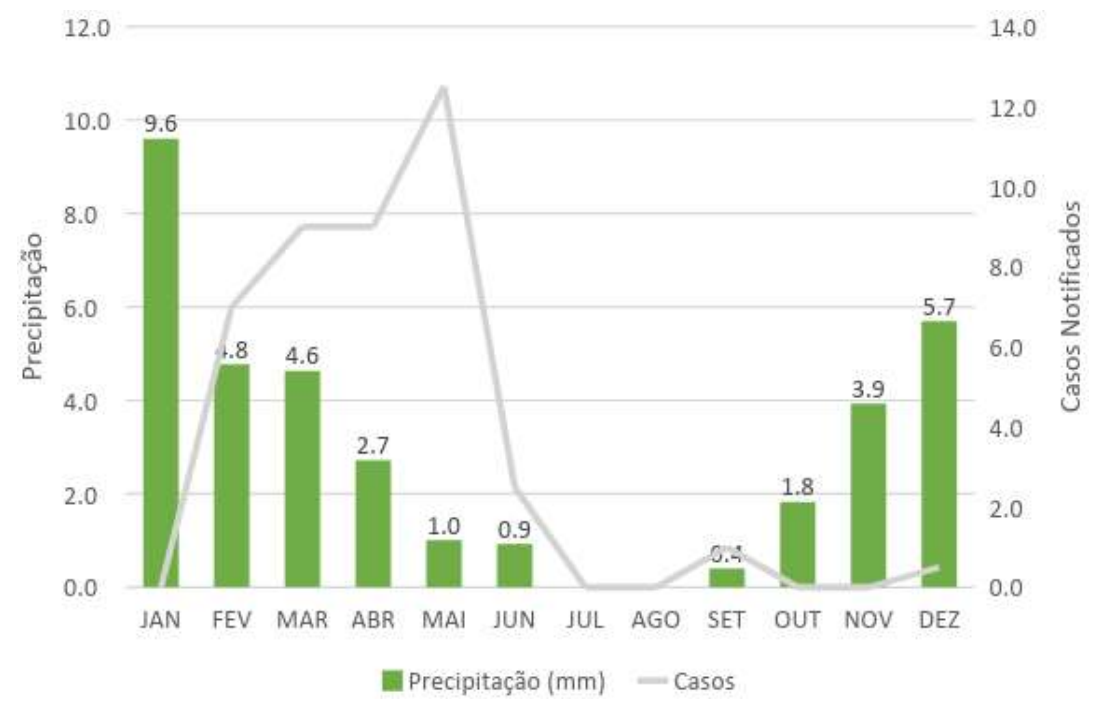

Fonte: Secretaria Municipal de Saúde de Balsas - MA.

No Brasil, os casos da doença têm sido reportados desde o final de 2014, embora seu marco maior tenha ocorrido no início de 2015, em amostras de soro de pacientes da cidade de Natal/RN (Zanluca, 2015) e de Camaçari/BA (Campos, 2015). As análises filogenéticas dos vírus isolados apresentaram 99\% de compatibilidade com a linhagem asiática, reportada em epidemias das Ilhas do Pacífico (Musso et al., 2014).

A vigilância epidemiológica fala de números e casos. Até 12 de março de 2016 (Semana Epidemiológica 10), eram 6.480 casos notificados, 1.349 descartados, 863 confirmados para microcefalia ou alterações sugestivas de infecção congênita causada pelo vírus Zika. Em 97 casos, confirmou-se a presença do vírus por exames específicos. Dessa forma, torna-se de extrema relevância estudos que apontem dados para Zika.

A Figura 4 mostra a incidência dos casos da febre Chikungunya e precipitação pluviométrica média entre os anos de 2016 - 2017. Os casos de febre Chikungunya entre 2016 - 1017 mostrou maior incidência nos meses de abril e junho, apesar do baixíssimo índice pluviométrico nesses meses. Nos meses de agosto e dezembro, apesar da precipitação ter um aumento crescente, os casos foram praticamente nulos. 
Figura 4: Precipitação pluviométrica média e casos de febre Chikungunya no município de Balsas - MA entre 2016 - 2017.

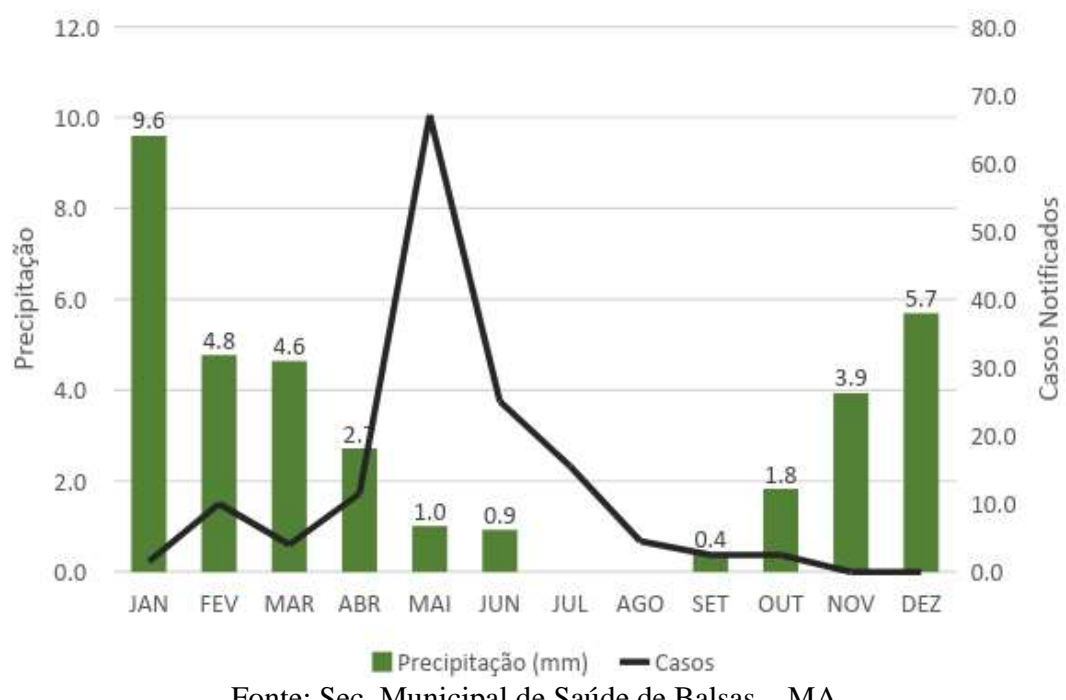

Fonte: Sec. Municipal de Saúde de Balsas - MA.

A Febre Chikungunya é uma doença muito semelhante a dengue, causada pelo vírus CHIKV, da família Togaviridae. Seu modo de transmissão é pela picada do mosquito Aedes aegypti infectado e, menos comumente, pelo mosquito Aedes albopictus (Tauil, 2001; Freitas et al., 2020). Embora a transmissão direta entre humanos não esteja tão demonstrada, considera - se a possibilidade da transmissão no útero da mãe para o feto. O período de incubação do vírus é de 4 a 7 dias, e a doença, na maioria dos casos, é autolimitante. A mortalidade em menores de um ano é de 0,4\%, podendo ser mais elevada em indivíduos com patologias associadas. No Brasil, a circulação do vírus foi identificada pela primeira vez em 2014.

O diagnóstico da doença é feito por exames laboratoriais de isolamento viral (Castro, 2016) e é importante para que se possa diferenciar o tipo de agravo e não ser confundido com doenças que também são transmitidos pelo Aedes como a Dengue (Canella, 2018).

\section{Considerações Finais}

Os dados aqui apresentaram que os casos de Zika vírus e febre Chikungunya tiveram uma maior frequência no município de Balsas no período de estiagem. Em contrapartida, a incidência do vírus da Dengue foi maior no período chuvoso. Assim, cabe ressaltar que o município de Balsas constitui um dos maiores centros urbano do sul da Maranhão, responsável pelo atendimento hospitalar de pessoas residentes em municípios vizinhos, tais como Fortaleza dos Nogueiras, Tasso Fragoso e Nova Colinas, o que torna ainda mais necessária a interiorização de laboratórios de referência para detecção de agentes etiológicos dos vetores. Dessa forma, considerando que o vetor permanece em atividade no cerrado balsense durante o período chuvoso e de estiagem, são necessárias ações contínuas de vigilância e controle epidemiológico do A. egypti. Estudos futuros sobre as variáveis contribuintes para a manutenção de arboviroses em áreas urbanas do município de Balsas devem ser realizados, com o intuito de monitorar os vetores, reduzindo os riscos de epidemias de Dengue, Zika e febre Chikungunya na região.

\section{Agradecimentos}

Agradecemos à Secretaria Municipal de Saúde do município de Balsas pela disponibilização dos dados secundários referentes à Dengue, Zika e Chikugunya, à Fundação de Amparo à Pesquisa e ao Desenvolvimento Cientifico e Tecnológico do Maranhão (FAPEMA) e a Universidade Federal do Maranhão (UFMA). 
Research, Society and Development, v. 11, n. 1, e44511123916, 2022

(CC BY 4.0) | ISSN 2525-3409 | DOI: http://dx.doi.org/10.33448/rsd-v11i1.23916

\section{Sugestão de trabalhos futuros}

- Relação dessas doenças com a COVID - 19

- Nova avaliação com um período de dados maior

- Saneamento Básico do Município e sua relação com essas Doenças

\section{Referências}

Araújo, J. M. G. D., Bello, G., Schatzmayr, H. G., Santos, F. B. D., \& Nogueira, R. M. R. (2009). Dengue virus type 3 in Brazil: a phylogenetic perspective. Memórias do Instituto Oswaldo Cruz, 104, 526-529.

Brasil. Ministério da Saúde. Descrição da doença (Dengue). Brasília, DF, 2014a. http://portalsaude.saude.gov.br/index.php/ descricao-da-doenca-dengue.

Faria, A. C., Santelli, S., de Brito, C. A. A., Luz, K. G., \& Neto, J. C. Chikungunya: Manejo Clínico.

Campos, G. S., Bandeira, A. C., \& Sardi, S. I. (2015). Zika virus outbreak, bahia, brazil. Emerging infectious diseases, 21(10), 1885.

Canella, C. Aspectos de imagem na febre Chikungunya. Radiologia Brasileira. 2017 Mar/Abr;50(2):V. http://www.scielo.br/pdf/rb/v50n2/pt_0100-3984-rb-5002-000V.pdf.

Cartão, R. de C. (2011). Dengue no Brasil: Abordagem geográfica na escala nacional / Rafael de castro catão - Presidente Prudente: xvi 169, f.:il.

Castro, A. P. C. R.; Lima, R. A.; \& Nascimento, J. S. (2016). Chikungunya: vision of the pain clinician. Revista Dor. São Paulo, 17(4):299-302.

Figueiredo, L. T. M. F. The recent arbovirus disease epidemic in Brazil. Revista da Sociedade Brasileira de Medicina Tropical. vol.48 no.3 Uberaba May/June 2015

Freitas, J. R., Nascimento, G. I. L. A., de Almeida Ferreira, D. S., Santiago, E. J. P., Moreira, G. R., da Silva, A. S. A., \& Cunha Filho, M. (2020). Análise espaço-temporal da incidência de febre Chikungunya no estado de Pernambuco. Research, Society and Development, 9(9), e288997114-e288997114.

Gubler, D.. Commentary: Ashburn PM, Craig CF. Experimental Investigations Regarding the Etiology of Dengue. The Journal of Infectious Diseases, v. 189, p. 744-1783, mai., 2004a.

Instituto Brasileiro de geografia e estatística. Balsas - Maranhão. IBGE. cidades.ibge.gov.br/brasil/ma/balsas/panorama.

Instituto Nacional de Meteorologia. INMET. http://www.inmet.gov.br/portal/index.php?r=bdmep/bdmep.

Lima-Costa, M. F., \& Barreto, S. M. (2003). Tipos de estudos epidemiológicos: conceitos básicos e aplicações na área do envelhecimento. Epidemiologia e serviços de saúde, 12(4), 189-201

Lopes, N., Nozawa, C., \& Linhares, R. E. C. (2014). Características gerais e epidemiologia dos arbovírus emergentes no Brasil. Revista Pan-Amazônica de Saúde, 5(3), 10-10. http://dx.doi.org/10.5123/S2176-62232014000300007

Maranhão. Secretaria Estadual de Saúde - SES/MA. http://www.saude.ma.gov.br/.

Medeiros Silva, F. C., de Souza Bezerra, H., de Araújo, A. O. C., de Carvalho, L. E. S., \& da Silva, J. A. (2021). Estudo temporal das arboviroses: Uma análise espacial. Research, Society and Development, 10(7), e10910716220-e10910716220

Musso, D., Nilles, E. J., \& Cao-Lormeau, V. M. (2014). Rapid spread of emerging Zika virus in the Pacific area. Clinical microbiology and infection, 20(10), O595-0596.

Oliveira, F. L. de; \& Dias, M. A. da S. (2016) Situação epidemiológica da dengue, Chikungunya e zika do estado do RN: uma abordagem necessária. Revista Humano Ser, 1(1).

Oliveira, E. H., Rodrigues, F. R., Coêlho, M. B., Verde, R. M. C. L., \& Sousa, F. D. C. A. (2020). Análise epidemiológica dos casos de dengue no Estado do Maranhão, Brasil. Research, Society and Development, 9(4), e78942491-e78942491.

Souza Martinuci, M., da Costa, M. R., Halabura, M. I. W., de Campos Bortolucci, W., Herrig, S. P. R., Fernandez, C. M. M., \& Gazim, Z. C. (2020). Levantamento epidemiológico dos casos de dengue, febre chikungunya e vírus Zika na macro região noroeste do Estado do Paraná no período de 2015 a 2020. Research, Society and Development, 9(12), e14591210950-e14591210950.

Rebêlo, J. M. M., Costa, J. M. L., Silva, F. S., Pereira, Y. N. O., \& Silva, J. M. D. (1999). Distribuição de Aedes aegypti e do dengue no Estado do Maranhão, Brasil. Cadernos de Saúde Pública, 15, 477-486.

Secretaria Municipal De Saúde De Secretária Municipal de Saúde. Prefeitura Municipal de Balsas. http://www.balsas.ma.gov.br/.

Tauil, P. L. (2001). Urbanização e ecologia do dengue. Cadernos de Saúde Pública, 17, S99-S102.

Zanluca, C., Melo, V. C. A. D., Mosimann, A. L. P., Santos, G. I. V. D., Santos, C. N. D. D., \& Luz, K. (2015). First report of autochthonous transmission of Zika virus in Brazil. Memórias do Instituto Oswaldo Cruz, 110(4), 569-572. 